\title{
PERBEDAAN TINGKAT KEMAMPUAN MENULIS BERITA DENGAN METODE EXAMPLES NON EXAMPLES VS METODE CORE (CONECTING, ORGANIZING, REFLECTING, EXTADING) SISWA KELAS VIII SMP NEGERI 7 PEMATANG SIANTAR
}

\author{
Junifer Siregar \\ Pendidikan Bahasa Indonesia FKIP Universitas HKBP Nommensen Pematang \\ Siantar
}

Email: Junifersiregar08480@gmail.com

\begin{abstract}
ABSTRAK
Penelitian ini bertujuan untuk mendeskripsikan perbedaan tingkat kemampuan siswa menulis berita dengan menggunakan model Examples Non Examples dan model Core (connecting, organizing, reflecting, extending). Metode penelitian yang digunakan adalah metode eksperimen. Hasil analisis data dilakukan dengan menggunakan uji perbedaan mean sampel tak berhubungan (Uji-t). Pengujian hipotesis membuktikan bahwa kemampuan menulis berita dengan menggunakan model Examples Non Examples adalah nilai $t_{\text {hitung }}(\mathrm{th})=2$, 908. Setelah dibandingkan pada tabel dengan taraf signifikan $95 \%$ dan $\mathrm{df}=\mathrm{n}_{1}+\mathrm{n}_{2}-2=30+30-2=58$, maka didapatlah nilai $t_{\text {tabel }}\left(t_{t}\right)=2,01$. Dari perbandingan di atas dapat disimpulkan bahwa nilai $t_{h}$ lebih besar dari $t_{t}$ pada taraf signifikansi $95 \%$, maka hipotesis diterima. Dari hasil penelitian ini, maka hasil belajar menulis berita dengan menggunakan model menggunakan model Examples Non Examples lebih baik dibandingkan dengan menggunakan model Core (connecting, organizing, reflecting, extending).
\end{abstract}

Kata Kunci : Menulis, Metode Examples Non Examples, Metode CORE (Connecting, Organiating, Reflecting, Extending) 


\begin{abstract}
This study aims to describe the different levels of students' ability to write news using the Examples Non Examples model and the Core model (connecting, organizing, reflecting, extending). The research method used is the experimental method. The results of data analysis were carried out by using the unrelated sample mean difference test (t-test). Hypothesis testing proves that the ability to write news using the Examples Non Examples model is the value of $\mathrm{t} \_(\text {count })(\mathrm{th})=2$, 908. After being compared to the table with a significant level of $95 \%$ and $\mathrm{df}=\mathrm{n} 1+\mathrm{n} 2-2=30+30-2=58$, then the value of $t \_t a b l e\left(t \_t\right)=2.01$. From the comparison above, it can be concluded that the value of $t \_h$ is greater than t_t at a significance level of $95 \%$, so the hypothesis is accepted. From the results of this study, the results of learning to write news using a model using the Examples Non Examples model is better than using the Core model (connecting, organizing, reflecting, extending)
\end{abstract}

Keywords: Writing, Examples Non Examples Method, CORE . Method

(Connecting, Organizing, Reflecting, Extending)

\section{PENDAHULUAN}

Pembelajaran bahasa Indonesia
diarahkan untuk meningkatkan
kemampuan peserta didik untuk
berkomunikasi dalam bahasa Indonesia
dengan baik dan benar, baik secara
lisan maupun tulisan. Bahasa dapat
dituliskan terutama bagi siswa SMP,

Pembelajaran bahasa Indonesia diarahkan untuk meningkatkan kemampuan peserta didik untuk dengan baik dan benar, baik secara Iisan maupun tulisan. Bahasa dapat dituliskan terutama bagi siswa SMP, banyak siswa yang menyepelekan pelajaran bahasa Indonesia. Kondisi tersebut berdampak pada kurang optimalnya kemampuan dan keterampilan berbahasa Indonesia para siswa. Keterampilan berbahasa ada empat, yaitu keterampilan menyimak, keterampilan berbicara, keterampilan membaca, dan keterampilan menulis). 
Dalam Kurikulum Tingkat

Satuan Pendidikan (KTSP) menulis merupakan keterampilan yang harus dimiliki seorang siswa. Keterampilan menulis teks berita merupakan salah satu keterampilan menulis yang terdapat di kelas VIII SMP sederajat, dengan Standar Kompetensi: mengungkapkan informasi dalam bentuk rangkuman, teks berita, slogan/poster dan Kompetensi Dasar: menulis teks berita secara singkat, padat, dan jelas.

Berdasarkan pengamatan peneliti pada siswa kelas VIII SMP Negeri 7 Pematangsiantar, terdapat kendala yang dialami siswa dalam menulis teks berita, yakni (1) siswa kesulitan dalam menyusun judul berita yang baik, (2) siswa kesulitan dalam menyusun teras berita (lead) dan body berita, (3) siswa kesulitan dalam menggunakan bahasa yang baik dan benar saat menulis teks berita, (4) pemilihan pendekatan dan media yang digunakan guru dalam pembelajaran kurang bervariasi. Kendala tersebut mengakibatkan hasil menulis teks berita siswa kelas VIII SMP Negeri 7
Pematangsiantar rendah. Hal ini dibuktikan, bahwa kemampuan siswa $\begin{array}{lllll}\text { kelas } & \text { VIII } & \text { SMP } & \text { Negeri } 7\end{array}$ Pematangsiantar rata-rata 67,5 , jauh di bawah KKM yang diharapkan.

Maka atas dasar inilah peneliti merasa perlu untuk melakukan penelitian. Diharapkan dari penelitian ini terjadi peningkatan kemampuan menulis teks berita siswa kelas VIII SMP NEGERI 7 Pematangsiantar.

Ada dua metode yang dianggap tepat dalam membandingkan kemampuan siswa dalam menulis teks berita, yaitu model EXAMPLES NON EXAMPLES vs model CORE (connecting, organizing, reflecting, extending).

Penelitian Nur Indria Fatmawat Imtikhana (2012) dengan judul Peningkatan Kemampuan Menulis Karangan Bahsa Indonesia Melalui Metode Example Non Example Dengan Media Gambar Pada Siswa Kelas IV SD Negeri Sambon 2 Kecamatan Banyudono Kabupaten Boyolali Tahun Pelajaran 2011/2012 menunjukkan bahwa penerapan metode Example non Example dapat meningkatkan 
ketrampilan mengarang siswa. Hal ini ditandai dengan adanya prosentase peningkatan nilai rata-rata mengarang siswa pada setiap siklusnya. Pada pra siklus siswa yang mencapai KKM sebanyak 7 siswa atau $36,84 \%$ dengan nilai rata-rata 59,94. Pada siklus I siswa yang mencapai KKM meningkat sebanyak 11 siswa dengan prosentase sebesar $57,89 \%$ dan nilai rata-rata 64,78, sedangkan pada siklus II siswa yang mencapai KKM meningkat menjadi 15 siswa dengan prosentase sebesar $78,94 \%$ dan nilai rata-rata 73 . Kesimpulan penelitian ini adalah melalui penerapan metode Example non Example dapat meningkatkan ketrampilan mengarang bahasa Indonesia Pada siswa kelas IV SD Negeri 02 Sambon

Penelitian selanjutnya, penelitian Hapsah S. Bakkari (2014) dengan judul Penerapan Model Example Non Example Dalam Menulis Karangan Deskripsi Pada Siswa Kelas IV SDN 1 Kabila Kabupaten Bone Bolang, menunjukan bahwa hasil yang dicapai siswa kelas IV yang berjumlah 32 orang siswa ternyata hanya 24 orang siswa yang mampu dengan kategori nilai tuntas, sedangkam 8 orang siswa kurang mampu dengan kategori nilai belum tuntas dalam menulis karangan deskripsi. hasil penelitian pada siklus I rata-rata 40,6 dan siklus II mencapai 82,00 dengan KKM 70,00. Dari hasil penelitian dapat disimpulkan bahwa dengan adanya penerapan model example non example dapat meningkatkan daya imajinasi siswa dalam menulis karangan deskripsi

Berdasarkan uraian di atas maka peneliti ingin mendeskripsikan perbedaan kemampuan menulis teks berita yang diajar dengan model Examples Non Examples dengan yang menggunakan model CORE (connecting, organizing, reflecting, extending).

Sesuai latar belakang masalah tersebut, maka rumusan masalah penelitian adalah "Apakah terdapat perbedaan yang signifikan pada tingkat kemampuan menulis teks berita siswa VIII SMP NEGERI 7 Pematangsiantar yang diajar dengan model EXAMPLES NON EXAMPLES vs model CORE 
(connecting, organizing, reflecting, extending)?

\section{METODE PENELITIAN}

\section{Metode Penelitian}

Metode penelitian pada dasarnya merupakan cara ilmiah untuk mendapatkan data dengan tujuan dan kegunaan tertentu. Adapun metode yang digunakan dalam penelitian ini adalah metode eksperimen. Metode ini digunakan untuk menguji hipotesis dan mendeskripsikan perbandingn dari kedua model yang diteliti.

Adapun desain eksperimental yang dipakai dalam penelitian ini adalah desain 5, yaitu:

\begin{tabular}{|c|c|c|c|}
\hline $\begin{array}{c}\text { Kelompo } \\
\mathrm{k}\end{array}$ & Prates & Variabel bebas & Pasca tes \\
\hline $\mathrm{E}$ & $\mathrm{Y} 1$ & $\mathrm{X}$ & $\mathrm{Y} 2$ \\
\hline $\mathrm{P}$ & $\mathrm{Y} 1$ & - & $\mathrm{Y} 2$ \\
\hline
\end{tabular}

\section{Lokasi Penelitian}

Lokasi yang menjadi pilihan peneliti untuk melakukan penelitian $\begin{array}{lll}\text { adalah } & \text { SMP } & \text { NEGERI }\end{array}$ Pematangsiantar.

\section{Populasi dan Sampel}

Menurut Sugiyono

(2011:90)

"Populasi adalah wilayah generalisasi yang terdiri atas: obyek/ subyek yang mempunyai kualitas dan karakteristik tertentu yang ditetapkan oleh peneliti untuk dipelajari dan kemudian ditarik kesimpulannya." Populasi pada penelitian ini adalah siswa kelas VIII SMP NEGERI 7 Pematangsiantar.

Sampel adalah bagian dari jumlah dan karakteristik yang dimiliki oleh populasi tersebut. Bila populasi besar, dan peneliti tidak mungkin mempelajari semua yang ada pada populasi, misalnya karna kerterbatasan dana, tenaga da waktu, maka peneliti dapat menggunakan sampel yang diambil dari populasi (Sugiyono, 2011:91).

Peneliti memilih dua kelompok atau dua kelas sebagai sampel, yaitu kelas VIII-A sebagai kelas eksperimen dan kelas VIII-B sebagai kelas pengendali. Masing-masing kelompok diberi perlakuan. Kelas eksperime diberi perlakuan model Examples Non Examples sedangkan kelas pengendali diberi perlakuan model CORE.

\section{Teknik Analisis Data}

Teknik analisi data yang digunakan dalam penelitian ini adalah 
dengan cara statistik yaitu Uji beda (Uji-t). Rumus uji-t adalah

$$
t=\frac{X_{1}-X_{2}}{\sqrt{\left(\frac{\sum X_{1}^{2}+\sum X_{2}^{2}}{n_{1}+n_{2}-2}\right)\left(\frac{1}{n_{1}}+\frac{1}{n_{2}}\right)}}
$$

\section{HASIL PENELITIAN}

\section{Uji Kesetaraan Kelompok}

Eksperimen dan Kelompok

Pengendali

\begin{tabular}{|c|c|c|c|c|c|}
\hline \multicolumn{3}{|c|}{ Eksperimen } & \multicolumn{3}{|c|}{ Pengendali } \\
\hline $\mathrm{X}_{1}$ & $\mathrm{x} 1$ & $x 1^{2}$ & $\mathrm{X}_{2}$ & $\mathrm{x} 2$ & $x 2^{2}$ \\
\hline 52 & 0,27 & 0,07 & 68 & 22,54 & 508,05 \\
\hline 64 & 12,27 & 150,55 & 24 & $-21,46$ & 460,53 \\
\hline 36 & $-15,73$ & 247,43 & 32 & $-13,46$ & 181,17 \\
\hline 64 & 12,27 & 150,55 & 24 & $-21,46$ & 460,53 \\
\hline 44 & $-7,73$ & 59,75 & 32 & $-13,46$ & 181,17 \\
\hline 60 & 8,27 & 68,39 & 52 & 6,54 & 42,77 \\
\hline 40 & $-11,73$ & 137,59 & 20 & $-25,46$ & 648,53 \\
\hline 52 & 0,27 & 0.07 & 24 & $-21,46$ & 460,53 \\
\hline 32 & $-19,73$ & 389,27 & 68 & 22,54 & 508,05 \\
\hline 52 & 0,27 & 0,07 & 28 & $-17,46$ & 304,85 \\
\hline 56 & 4,27 & 18,23 & 24 & $-21,46$ & 460,53 \\
\hline 32 & $-19,73$ & 389,27 & 32 & $-13,46$ & 181,17 \\
\hline 40 & $-11,73$ & 137,59 & 44 & $-1,46$ & 2,13 \\
\hline 28 & $-23,73$ & 563,11 & 40 & $-5,46$ & 29,81 \\
\hline 88 & 36,27 & 1315,5 & 68 & 22,54 & 508,05 \\
\hline & & 1 & & & \\
\hline 88 & 36,27 & 1315,5 & 28 & $-17,46$ & 304,85 \\
\hline & & 1 & & & \\
\hline 68 & 16,27 & 264,71 & 68 & 22,54 & 508,05 \\
\hline 60 & 8,27 & 68,39 & 80 & 34,54 & 1193,01 \\
\hline 48 & $-3,73$ & 13,91 & 44 & $-1,46$ & 2,13 \\
\hline 36 & $-15,73$ & 247.43 & 48 & 2,54 & 6,45 \\
\hline 48 & $-3,73$ & 13,91 & 68 & 22,54 & 508,05 \\
\hline 44 & $-7,73$ & 59,75 & 64 & 18,54 & 343,73 \\
\hline
\end{tabular}

\begin{tabular}{|c|c|c|c|c|c|}
\hline 36 & $-15,73$ & 247,43 & 24 & $-21,46$ & 460,53 \\
\hline 40 & $-11,73$ & 137,59 & 32 & $-13,46$ & 181,17 \\
\hline 40 & $-11,73$ & 137,59 & 76 & 30,54 & 932,69 \\
\hline 52 & 0,27 & 0,07 & 32 & $-13,46$ & 181,17 \\
\hline 60 & 8,27 & 68,39 & 44 & $-1,46$ & 2,13 \\
\hline 76 & 24,27 & 589,03 & 80 & 34,54 & 1193,01 \\
\hline 68 & 16,27 & 264,71 & 60 & 14,54 & 211,41 \\
\hline 48 & $-3,73$ & 13,91 & 36 & $-9,46$ & 89,49 \\
\hline & & & $\sum \mathrm{X}$ & & \\
$\sum \mathrm{X}_{1=}$ & & & $2=$ & & \\
1552 & & $\mathrm{x}_{1}^{2}=$ & 13 & & \\
& & 7069,7 & 64 & & $\mathrm{x}^{2}=11055,42$ \\
$\mathrm{X}_{1=}$ & & 8 & $\overline{\mathrm{X}}_{2=}$ & & \\
51,73 & & & 45, & & \\
& & & 46 & & \\
& & & & & \\
\hline
\end{tabular}

$$
\begin{array}{ll}
\mathrm{X}_{1}=\mathrm{X}_{1}-\mathrm{X}_{1} & -\overline{\mathrm{X}_{2}}=\mathrm{X}_{2} \cdot \mathrm{X}_{2} \\
\mathrm{~N}_{1}=30 \text { dan } & \mathrm{N}_{2}=30
\end{array}
$$

$$
t=\frac{\bar{X}_{1}-\bar{X}_{2}}{\sqrt{\left(\frac{\sum x_{1}^{2}+\sum x_{2}^{2}}{n_{1}+n_{2}-2}\right)\left(\frac{1}{n_{1}}+\frac{1}{n_{2}}\right)}}
$$

$$
\begin{aligned}
\text { 2. } t & =\frac{51,73-45,46}{\sqrt{\left(\frac{7069,78+11055,42}{30+30-2}\right)\left(\frac{1}{30}+\frac{1}{30}\right)}} \\
\text { 3. } t & =\frac{6,27}{\sqrt{(312,49)(0,06)}} \\
\text { 4. } t & =\frac{6,27}{\sqrt{18,74}}
\end{aligned}
$$

5. $t=1,448$

6.

Berdasarkan perhitungan diperoleh: th $=1,448$, Setelah dikonsultasikan dengan tabel $B$ dengan taraf 
signifikansi 95\% diperoleh hasil $\mathrm{t}_{\mathrm{d} f 58}=$ 2,01 (interpolasi) tidak signifikan p> 0,05 . Dengan demikian uji kesetaraan terpenuhi

\section{Pengujian Hipotesis}

\begin{tabular}{|c|c|c|c|c|c|}
\hline \multicolumn{3}{|c|}{ Eksperimen } & \multicolumn{3}{|c|}{ Pengendali } \\
\hline$\overline{X_{1}}$ & $\mathrm{X} 1$ & $\mathrm{X} 1^{2}$ & $\mathrm{X}_{2}$ & $\mathrm{X} 2$ & $\mathrm{X}_{2}^{2}$ \\
\hline 68 & $\begin{array}{c}- \\
1,46\end{array}$ & 2,13 & 72 & 9,87 & 97,41 \\
\hline 76 & 6,54 & 42,77 & 52 & $\begin{array}{c}- \\
10,1 \\
3\end{array}$ & 102,61 \\
\hline 64 & $\begin{array}{c}- \\
5,46\end{array}$ & 29,81 & 56 & $\begin{array}{c}- \\
6,13\end{array}$ & 37,57 \\
\hline 80 & $\begin{array}{c}10,5 \\
4\end{array}$ & $\begin{array}{c}111,0 \\
9\end{array}$ & 56 & $\begin{array}{c}- \\
6,13\end{array}$ & 37,57 \\
\hline 68 & $\begin{array}{c}- \\
1,46\end{array}$ & 2,13 & 72 & 9,87 & 97,41 \\
\hline 72 & 2,54 & 6,45 & 60 & $\begin{array}{c}- \\
2,13\end{array}$ & 4,53 \\
\hline 68 & $\begin{array}{c}- \\
1,46\end{array}$ & 2,13 & 48 & $\begin{array}{c}- \\
14,1 \\
3\end{array}$ & 199,65 \\
\hline 72 & 2,54 & 6,45 & 52 & $\begin{array}{c}- \\
10,1 \\
3\end{array}$ & 102,61 \\
\hline 64 & $\begin{array}{c}- \\
5,46\end{array}$ & 29,81 & 60 & $\begin{array}{c}- \\
2,13\end{array}$ & 4,53 \\
\hline 68 & $\begin{array}{c}- \\
1,46\end{array}$ & 2,13 & 52 & $\begin{array}{c} \\
10,1 \\
3\end{array}$ & 102,61 \\
\hline 72 & 2,54 & 6,45 & 48 & $\begin{array}{c}- \\
14,1 \\
3\end{array}$ & 199,65 \\
\hline 60 & $\begin{array}{c}- \\
9,46\end{array}$ & 89,49 & 56 & $\begin{array}{c}- \\
6,13\end{array}$ & 37,57 \\
\hline
\end{tabular}

\begin{tabular}{|c|c|c|c|c|c|}
\hline 68 & $\begin{array}{c}- \\
1,46\end{array}$ & 2,13 & 76 & $\begin{array}{c}13,8 \\
7\end{array}$ & 192,37 \\
\hline 72 & 2,54 & 6,45 & 68 & 5,87 & 34,45 \\
\hline 80 & $\begin{array}{c}10,5 \\
4\end{array}$ & $\begin{array}{c}111,0 \\
9\end{array}$ & 60 & $\begin{array}{c}- \\
2,13\end{array}$ & 4,53 \\
\hline 92 & $\begin{array}{c}22,5 \\
4\end{array}$ & $\begin{array}{c}508,0 \\
5\end{array}$ & 68 & 5,87 & 34.45 \\
\hline 72 & 2,54 & 6,45 & 92 & $\begin{array}{c}29,8 \\
7\end{array}$ & 892,21 \\
\hline 76 & 6,54 & 42,77 & 60 & $\begin{array}{c}- \\
2,13\end{array}$ & 4,53 \\
\hline 60 & $\begin{array}{c}- \\
9,46\end{array}$ & 89,49 & 60 & $\begin{array}{c}- \\
2,13\end{array}$ & 4,53 \\
\hline 60 & $\begin{array}{c}- \\
9,46\end{array}$ & 89,49 & 72 & 9,87 & 97,41 \\
\hline 72 & 2,54 & 6,45 & 68 & 5,87 & 34,45 \\
\hline 68 & $\begin{array}{c}- \\
1,46\end{array}$ & 2,13 & 64 & 1,87 & 3,49 \\
\hline 64 & $\begin{array}{c}- \\
5,46\end{array}$ & 29,81 & 44 & $\begin{array}{c}- \\
18,1 \\
3\end{array}$ & 328,69 \\
\hline 64 & $\begin{array}{c}- \\
5,46\end{array}$ & 29,81 & 48 & $\begin{array}{c}- \\
14,1 \\
3\end{array}$ & 199,65 \\
\hline 48 & $\begin{array}{c}- \\
21,4 \\
6\end{array}$ & $\begin{array}{c}460,5 \\
3\end{array}$ & 88 & $\begin{array}{c}25,8 \\
7\end{array}$ & 669,25 \\
\hline 68 & $\begin{array}{c}- \\
1,46\end{array}$ & 2,13 & 48 & $\begin{array}{c}- \\
14,1 \\
3\end{array}$ & 199,65 \\
\hline 68 & $\begin{array}{c}- \\
1,46\end{array}$ & 2,13 & 52 & $\begin{array}{c}- \\
10,1 \\
3\end{array}$ & 102,61 \\
\hline 84 & $\begin{array}{c}14,5 \\
4\end{array}$ & $\begin{array}{c}211,4 \\
1\end{array}$ & 80 & $\begin{array}{c}17,8 \\
7\end{array}$ & 319,33 \\
\hline 72 & 2,54 & 6,45 & 64 & 1,87 & 3,49 \\
\hline 64 & $\begin{array}{c}- \\
5,46\end{array}$ & 29,81 & 68 & 5,87 & 34,45 \\
\hline $\begin{array}{c}\sum \mathrm{X}_{1} \\
= \\
208 \\
4\end{array}$ & & $\begin{array}{c}\mathrm{x}_{1}^{2}= \\
1967, \\
42\end{array}$ & $\begin{array}{c}\sum \mathrm{X}_{2} \\
= \\
186 \\
4\end{array}$ & & $\begin{array}{c}\mathrm{x}^{2}=4183, \\
26\end{array}$ \\
\hline
\end{tabular}




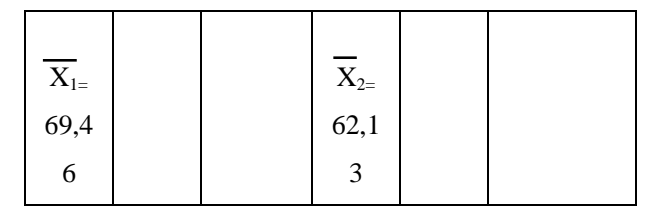

$\mathrm{X} 1=\mathrm{X}_{1}-\overline{\mathrm{X}}_{1} \quad \mathrm{X} 2=\mathrm{X}_{2}-\overline{\mathrm{X}}_{2}$

$\mathrm{N}_{1}=30$ dan $\mathrm{N}_{2}=30$

$t=\frac{\bar{X}_{1}-\bar{X}_{2}}{\sqrt{\left(\frac{\sum x_{1}^{2}+\sum x_{2}^{2}}{n_{1}+n_{2}-2}\right)\left(\frac{1}{n_{1}}+\frac{1}{n_{2}}\right)}}$

$t=\frac{69,46-62,13}{\sqrt{\left(\frac{1967,42+4317,64}{30+30-2}\right)\left(\frac{1}{30}+\frac{1}{30}\right)}}$

$t=\frac{7,33}{\sqrt{(106,04)(0,06)}}$

$t=\frac{7,33}{\sqrt{6,36}}$

$t=2,908$

Untuk pengujian hipotesis dilakukan dengan uji-t yaitu dengan membedakan rata-rata hasil belajar post-test siswa eksperimen dengan hasil post-test kelas pengendali. Hipotesis statistika:

Ho : $\mu_{1}=\mu_{2}$

$\mathrm{Ha} \% \mu_{1}=\mu_{2}$

Berdasarkan perhitungan pada lampiran 4 diperoleh $\quad t=2,908$

p-ISSN 2648-8600 sedangkan pada tabel $=2,0195 \% \mathrm{k}_{\mathrm{df} 58}$ $=2,01$ signifikan pada $\mathrm{p}<0,05$. Dengan demikian Ho ditolak. Dengan penolakan Ho maka Ha diterima, artinya terdapat perbedaan yang signifikan terhadap tingkat kemampuan menulis berita siswa kelas VIII SMP Negeri 7 Pematangsiantar yang diajar dengan model EXAMPLES NON EXAMPLES vs model CORE (connecting, organizing, reflecting, extending).

\section{Pembahasan Hasil Penelitian}

Berdasarkan analisis yang telah dilakukan sebelumnya dengan pengujian hipotesis, maka dapat disimpulkan bahwa ada perbedaan yang signifikan tingkat kemampuan menulis teks berita siswa kelas VIII SMP Negeri 7 Pematangsiantar yang diajar dengan model EXAMPLES NON EXAMPLES dibandingkan dengan model CORE (connecting, organizing, reflecting, extending). Hal ini karena pembelajaran dengan model EXAMPLES NON EXAMPLES melibatkan dan menjadikan siswa sebagai subjek pembelajaran dengan 
memberikan gambar-gambar yang relevan untuk menarik perhatian siswa serta untuk menggali daya pikir siswa, sehingga siswa lebih mudah menuangkan ide-ide yang telah ia miliki ke dalam bentuk tulisan.

Keunggulan dari model EXAMPLES NON EXAMPLES dapat dilihat dari skor rata-rata siswa. Ratarata skor kelompok eksperimen memiliki perbedaan yang signifikan dibandingkan dengan kelompok pengendali, yakni pada kelompok eksperimen 69,46 sedangkan pada kelompok pengendali 62,13. Keefektifan model ini tampak dengan keseriusan siswa memperhatikan gambar yang telah disediakan dan kemudian menuangkan ide-ide yang ia dapatkan dari memperhatikan gambar, tidak hanya itu siswa juga dapat saling bertukar ide dengan teman yang disebelahnya. Sedangkan pada kelompok pengendali, siswa aktif namun hasil menulis berita yang mereka tulis kurang bagus, karena masih banyak siswa yang menggunakan kalimat yang kurang efektif serta penggunaan tanda baca masih kurang juga.

Secara kuantitatif perbedaan skor antara model EXAMPLES NON EXAMPLES dengan model CORE (connecting, organizing, reflecting, extending) adalah 69,46 - 62,13, sedangkan secara kualitatif nilai 66,46 merupakan nilai yang lebih tinggi dibandingkan dengan nilai 62,13. Dengan demikian dapat disimpulkan kemampuan menulis teks berita yang diajar dengan menggunakn model EXAMPLES NON EXAMPLES lebih tinggi perolehan nilainya dibandingkan yang diajar dengan model CORE (connecting, organizing, reflecting, extending).

Dari hasil penelitian ini diharapkan dapat menjadi acuan bagi para guru, khususnya guru bahasa Indonesia bahwa kemampuan menulis teks berita siswa perlu ditingkatkan terutama bagi siswa menengah pertama. Perbedaan penerapan kedua model tersebut mejadi gambaran bahwa model EXAMPLES NON EXAMPLES lebih efektif daripada model CORE (connecting, organizing, reflecting, extending) 
dengan perolehan skor 69,46 dan 62,13.

Dengan demikian guru dapat menerapkan model EXAMPLES NON EXAMPLES dalam pembelajaran menulis berita ataupun pembelajaran lain. Guru dapat menjadikan hasil penelitian ini sebagai acuan. Diharapkan juga, guru dapat menciptakan suasana belajar yang menyenangkan, salah satunya dengan memilih model-model pembelajaran yang menarik agar siswa semakin bersemangat dan tentu saja agar prestasi belajar siswa semakin baik.

\section{DAFTAR PUSTAKA}

Alwi, Hasan, dkk. 2008. Kamus Besar Bahasa Indonesia. Jakarta: Gramedia Pustaka Utama.

Arikunto, Suharsimi. 2010. Prosedur Penelitian Suatu Pendekatan Praktik. Jakarta: Rineka Cipta.

Ary, Donal, dkk. Pengantar Penelitian dalam Pendidikan. Surabaya: Usaha Nasional.
Bakkari, Hapsah S. 2014. Penerapan Model Example Non Example Dalam Menulis Karangan Deskripsi Pada Siswa Kelas IV SDN 1 Kabila Kabupaten Bone Bolang.

file://C:/Users/USER/Downloa ds/4322-4312-1-PB.pdf.

Diunduh pada tanggal 02 Juni 2016.

Imtikhana, Nur Indria F. 2012. Peningkatan Kemampuan Menulis Karangan Bahsa Indonesia Melalui Metode Example Non Example Dengan Media Gambar Pada Siswa Kelas IV SD Negeri Sambon 2 Kecamatan Banyudono Kabupaten Boyolali Tahun Pelajaran 2011/2012. http://eprints.ums.ac.id/19127/1 5/NASKAH_PUBLIKASI.pdf. Diunduh pada tanggal 02 Juni 2016.

Istarani. 2012. 58 Model Pembelajaran Inovatif. Medan: Media Persada. 
K, Jingga Z. 2009. Bagaimana Menulis

Berita?. Bandung: Puri Pustaka.

Kamshsyahdan. 2010. Pembelajaran

Menulis dengan Strategi

Pemodelan. Diunduh dari

http://www.kamsahsyahdan.wo

rdpress.com

Ks, Usman. 2009. Television News

Reporting \& Writing. Bogor:

Ghalia Indonesia.

Mardalis. 2002. Metode Penelitian

Suatu Pendekatan Proposal.

Jakarta: Bumi Aksara.

Mulyadi. 2010. Peningkatan

Kemampuan Membaca

Permulaan Melalui Model

Pembelajaran Kooperatif

Metode CORE Pada Siswa

Kelas 1 Sekolah Dasar.

https://core.ac.uk/download/file s/478/12345224.pdf. Diunduh pada tanggal 02 Juni 2016.

Murthado, Ali. 2007. Menulis di Surat

Kabar Gampang:Teknik

Penulisan Artikel, Feature dan

Resensi. Medan: Wal Ashri

Publishing.
Ngalimun. 2013. Strategi dan Model Pembelajaran.

Yogyakarta:Aswaja Pressindo.

Nurul, Hidayati. 2012. Penerapan Model Pembelajaran CORE (connecting, organazing, reflecting, extending). Diunduh dari

http://www.repository.upi.edu

Olii, Helena. 2007. Berita dan Informasi. Jakarta: PT. Indeks.

Panuju, Redi. 2005. Panduan Menulis Untuk Pemula. Yogyakarta: Pustaka Pelajar.

Putra, Masri Sareb. 2006. Teknik Menulis Berita \& Feature. Jakarta: PT. Indeks.

Sugiyono. 2011. Metode Penelitian Administrasi. Bandung: Alfabeta.

Tarigan, Hendri Guntur. 1986. Menulis Sebagai Suatu Keterampilan Berbahasa. Bandung: Angkasa. Tondowidjojo, John. 1983. Media Massa \& Pendidikan. Yogyakarta: Kanisius. 
Wahyudi, J.B. 1991. Komunikasi

Jurnalistik. Bandung: Alumni

Wati. 2012. Keefektifitasan Model

Proyek Respons Kreatif Dalam

Pembelajaran Menulis Teks

Berita. Diunduh dari

http://www.repository.upi.edu

Yunus, Syarifudin. 2010. Jurnalistik

Terapan. Bogor: Ghalia

Indonesia. 